\title{
Upconversion Nanoparticles Encapsulated with Amorphous Silica and Their Emission Quenching by FRET: A Nanosensor Excited by NIR for Mercury Detection
}

\author{
Wei Wu ${ }^{1,2}$, Wei Wei ${ }^{1,2}$, Dingli $\mathrm{Xu}^{3}$, Yunpeng Liu ${ }^{4}$, Jin Li ${ }^{5, *}$, Kaifeng Gan ${ }^{5, *}$ and Liang Liu ${ }^{6}$ \\ 1 Hwa Mei Hospital, University of Chinese Academy of Sciences, Ningbo 315010, China; \\ fiennes.wu@foxmail.com (W.W.); weiwei_nb@163.com (W.W.) \\ 2 Ningbo Institute of Life and Health, University of Chinese Academy of Sciences, Ningbo 315010, China \\ 3 The Affiliated Hospital of Medical School of Ningbo University, Ningbo 315000, China; xudingliwo@126.com \\ 4 Faculty of Electronics \& Computer, Zhejiang Wanli University, Ningbo 315000, China; liuypjoy@163.com \\ 5 Li Huili Hospital Affiliated to Ningbo University, Ningbo 315211, China \\ 6 School of Materials Science \& Engineering, Jiangsu University, Zhenjiang 212013, China; \\ reserch419@outlook.com \\ * Correspondence: lijin@nbu.edu.cn (J.L.); gankaifeng@nbu.edu.cn (K.G.)
}

Citation: Wu, W.; Wei, W.; Xu, D.;

Liu, Y.; Li, J.; Gan, K.; Liu, L.

Upconversion Nanoparticles

Encapsulated with Amorphous Silica and Their Emission Quenching by FRET: A Nanosensor Excited by NIR for Mercury Detection. Crystals 2021, 11, 104. https://doi.org/10.3390/ cryst11020104

Received: 23 December 2020

Accepted: 18 January 2021

Published: 25 January 2021

Publisher's Note: MDPI stays neutral with regard to jurisdictional claims in published maps and institutional affiliations.

Copyright: (c) 2021 by the authors Licensee MDPI, Basel, Switzerland. This article is an open access article distributed under the terms and conditions of the Creative Commons Attribution (CC BY) license (https:/ / creativecommons.org/licenses/by/ $4.0 /)$.

\begin{abstract}
Near-infrared (NIR) region has been considered as a diagnostic window since it avoids sample autofluorescence and light scattering. Upconversion nanoparticles (UCNPs) convert NIR light into high energy excitation light, making them a suitable excitation source for nanoprobes with deep penetration depth and high signal-to-noise ratio. The current work reported a rhodaminederived probe for the detection of $\mathrm{Hg}$ (II). Corresponding absorption and emission responses for $\mathrm{Hg}(\mathrm{II})$ and detailed recognizing mechanism were discussed. An absorption titration experiment was performed. It was found that $\mathrm{Hg}$ (II) directly bonded with probe with chemical stoichiometry of 1:1, its association constant was calculated as $2.59 \times 10^{5} \mathrm{M}^{-1}$. Such a high value indicated a direct coordination affinity between $\mathrm{Hg}$ (II) and this rhodamine-derived probe. Most metal cations exerted no increasing effect on the probe emission or absorption, exhibiting good sensing selectivity of probe towards $\mathrm{Hg}$ (II). Upconversion nanoparticles (UCNPs) were firstly encapsulated with silica $\left(\mathrm{SiO}_{2}\right)$ and then bonded with the probe via a covalent bond. Given a near-infrared (NIR) laser excitation with wavelength of $980 \mathrm{~nm}$, this probe, (E)-2-((3', $6^{\prime}$-bis(diethylamino)-2', $7^{\prime}$-dimethyl-3oxospiro[isoindoline-1, $9^{\prime}$-xanthen]-2-yl)imino)acetaldehyde (denoted as RHO), captured the energy of UCNPs via a FRET (fluorescence resonance energy transfer) path, resulting in the emission quenching of UCNPs. This composite system showed linear sensing behavior towards $\mathrm{Hg}(\mathrm{II})$ with high selectivity, which was similar to the case of pure probe. No probe emission, however, was observed from the composite system, which was different from the case of most literature reports. The self-quenching between probe molecules was claimed responsible for the probe emission, which was confirmed by experiment result and analysis. To the best of our knowledge, this is the first demonstration of covalently integrating $\mathrm{SiO}_{2}$-coated UCNPs with a rhodamine-derived probe for $\mathrm{Hg}(\mathrm{II})$ sensing.
\end{abstract}

Keywords: UCNPs; IR laser excitation; $\mathrm{SiO}_{2}$ encapsulation; mercury cation

\section{Introduction}

Mercury and its compounds are widely distributed in natural environment and industrial manufactory. They have been classified as the most toxic matters and thus are considered as a human health threat [1]. Unfortunately, mercury and its compounds are not degradable and consequently accumulated via food chain, bringing more harm to the top terminal of the food chain, which means human beings. Human brains and nervous systems are most sensitive to mercury and its compounds [1,2]. In this case, the identification and recognition of $\mathrm{Hg}^{2+}$ ions and water-soluble compounds have been 
listed as a critical task in environmental protection and medical treatment. As a representative analyte, $\mathrm{Hg}^{2}$ is usually used to develop $\mathrm{Hg}$-sensing systems. There have been $\mathrm{Hg}^{2+}$-sensing systems based on pure organic probes and nanomaterials [3-6], which are, however, usually excited by high energy light within UV region. An obvious problem is the autofluorescence and thus low signal-to-noise ratio which compromises sensing performance and photo-oxidizes sensing probes. A secondary energy transfer mechanism has been proposed to solve this issue, using near-infrared (NIR) laser as excitation energy $[7,8]$. As a consequence, the development for sensing probes excited by NIR laser have harvested much research attention.

In most NIR-excited sensing systems, a secondary energy transfer mechanism is applied, using upconversion nanoparticles (UCNPs) as the secondary excitation source. UCNPs convert the low-energy NIR emission into high energy and then excite sensing probes, which has attracted research interests in the fields of analytical sensing and bioimaging [9-11]. Many literatures have concluded the virtues of using UCNPs as the secondary excitation source, including long-rage Stokes shift, good biocompatibility, low background luminescence noise and deep penetration depth in bio-samples [12-15]. Some sensing systems have been successfully developed for the recognition of DNA, avidin, cations and anions [16-18]. A problem facing these UCNPs is their hydrophobic surface which is highly incompatible with $\mathrm{Hg}^{2+}$ ions in aqueous media, leading to phase separation and thus poor sensing performance. Modifying the hydrophobic surface of UCNPs is then proposed to solve this problem. Dionne and coworkers have reported the Forster resonant energy transfer in a core-shell-shell structure with bright upconversion emission [19]. Lee and coworkers developed a NIR-to-NIR LRET system for homogeneous competitive immunoassay based on UCNPs [20]. Liu and coworkers reported a review article about the strategy for constructing upconversion luminescence nanoprobes to improve signal contrast [21]. In the meanwhile, the modification of UCNPs inevitably increases their size and compromises their fluent energy transfer to energy acceptors such as sensing probes.

In the present work, we encapsulate hydrophobic UCNPs with amorphous silica $\left(\mathrm{SiO}_{2}\right)$ which is highly hydrophilic. Then a rhodamine-derived probe (E)-2-((3',6'-bis(diethylamino)$2^{\prime}, 7^{\prime}$-dimethyl-3-oxospiro[isoindoline-1, $9^{\prime}$-xanthen]-2-yl)imino)acetaldehyde (denoted as $\mathrm{RBO}$ ) is covalently immobilized onto this $\mathrm{SiO}_{2}$ layer, acting as the energy acceptor for UCNPs. Given the excitation of NIR laser, this composite structure is supposed to show a selective and sensitive recognition for $\mathrm{Hg}^{2+}$ ions with low autofluorescence noise. Scheme 1 details the design route for this composite structure which is mentioned as ${\mathrm{UCNPs} @ \mathrm{SiO}_{2}-}^{-}$ RBO. Bright green emission light is observed by naked eyes from UCNPs@SiO $2-\mathrm{RBO}$ nanoparticles under the excitation of NIR laser of $980 \mathrm{~nm}$. With increasing $\mathrm{Hg}^{2+}$ concentrations, this upconversion emission is quenched obviously, showing emission quenching signal. On the other hand, there is no obvious increasing RBO emission during this procedure. A primary analysis suggests that $\mathrm{RBO}$ emission energy is consumed via a non-radiative path via the self-absorption of ground state $\mathrm{RBH}$ molecules.

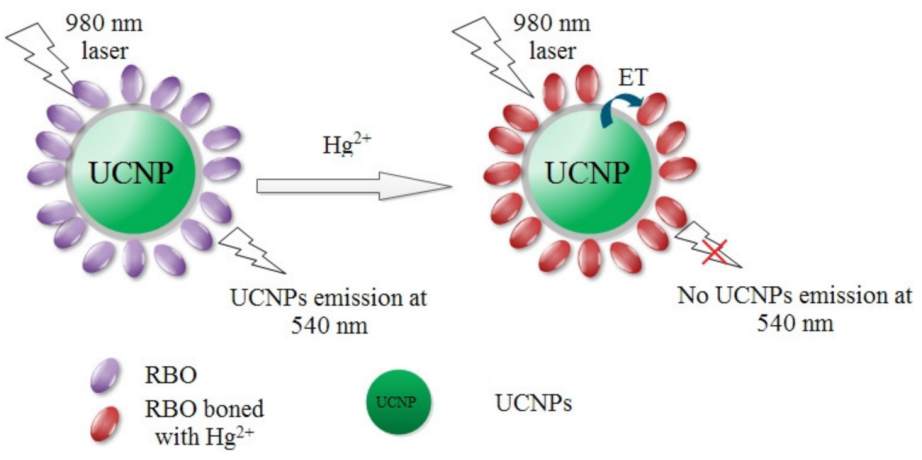

Scheme 1. The design route for upconversion nanoparticles (UCNPs)@SiO $2-\mathrm{RBO}$ and its working strategy. 


\section{Experimental Section}

\subsection{Reagents}

The starting chemical reagents were purchased and used as they were with no purifications. $\mathrm{RE}$ oxides, including $\mathrm{Y}_{2} \mathrm{O}_{3}, \mathrm{Yb}_{2} \mathrm{O}_{3}$ and $\mathrm{Er}_{2} \mathrm{O}_{3}$, were supplied by Yingshui Chemical Reagent Company. Corresponding RE chlorides, including $\mathrm{YCl}_{3}, \mathrm{YbCl}_{3}$ and $\mathrm{ErCl}_{3}$, were synthesized by soaking $\mathrm{RE}$ oxides in concentrated $\mathrm{HCl}$ and then vaporizing excess solvent water. Bulk crystals were obtained by vacuum evaporation at $30^{\circ} \mathrm{C}$. The other compounds, such as Oleic acid (OA, 90\%), 1-octadecene (ODE, 90\%) and polyoxyethylene (5) nonylphenyl ether (Igepal CO-520, Mn = 441), and (3-amino-propyl) triethoxysilane (APS, $\geq 98 \%$ ), were supplied by Beijing InnoChem Science and Technology Co., Ltd. Some common chemical reagents, including $\mathrm{NH}_{4} \mathrm{~F}, \mathrm{NaOH}$, tetraethylorthosilicate (TEOS), rhodamine B, hydrazine hydrate (85\%) and glyoxal, were supplied by Tianjin Chemical Reagents Company. Solvent water was redistilled twice before usage.

\subsection{Equipment and Method}

Transmission electron microscopy (TEM) and field-emission scanning electron microscopy (FE-SEM) images were provided by a JEM-2010 transmission electron microscope and a Hitachi S-4800 microscope. IR spectra were collected using a Bruker Vertex 70 FT-IR spectrophotometer. XRD curves were collected using a Bruker D4 X-ray diffractometer, $\mathrm{Cu} \mathrm{K}$ radiation $(40 \mathrm{kV}, 40 \mathrm{~mA})$. Thermogravimetric analysis (TGA) was finished by a Perkin-Elmer thermal analyzer. Luminescence spectra were recorded by a Hitachi F-4500 spectrophotometer, excited by a CW NIR laser $(980 \mathrm{~nm})$.

\subsection{The Synthesis for Silica Coated UCNPs}

The hydrophobic UCNPs were firstly synthesized following a literature procedure [21]. A typical run was briefly described as follows. A mixture of $\mathrm{YCl}_{3}(0.8 \mathrm{mmol}), \mathrm{YbCl}_{3}$ $(0.18 \mathrm{mmol})$ and $\mathrm{ErCl}_{3}(0.02 \mathrm{mmol})$ in oleic acid $(6 \mathrm{~mL})$ and octadecene $(15 \mathrm{~mL})$ was loaded into a flask and then heated at $160^{\circ} \mathrm{C}$. After cooling, methanol $(10 \mathrm{~mL}), \mathrm{NaOH}(2.5 \mathrm{mmol})$ and $\mathrm{NH}_{4} \mathrm{~F}(4 \mathrm{mmol})$ were added into the flask and stirred for half an hour. The resulting mixture was firstly heated at $70^{\circ} \mathrm{C}$ for $20 \mathrm{~min}$, then at $100^{\circ} \mathrm{C}$ for $10 \mathrm{~min}$ and finally at $300^{\circ} \mathrm{C}$ for $90 \mathrm{~min}$, within an Ar atmosphere. After natural cooling, cold ethanol was added, white solid was obtained and cleaned with ethanol/water $(1: 1 \mathrm{v} / \mathrm{v})$. The collected nanocrystals were dispersed in cyclohexane the later use.

A mixture of CO-520 $(0.1 \mathrm{~mL})$, cyclohexane $(6 \mathrm{~mL})$, hydrophobic UCNPs cyclohexane solution $(0.01 \mathrm{M}, 4 \mathrm{~mL})$ was stirred for $5 \mathrm{~min}$, then CO-520 $(0.4 \mathrm{~mL})$ and ammonia $(0.08 \mathrm{~mL}$, $30 \%$ ) were added. The resulting mixture was treated with ultrasonic bath for $30 \mathrm{~min}$, then TEOS $(0.04 \mathrm{~mL})$ was added. The resulting mixture was stirred at room temperature for two days. Acetone was added, and white solid was obtained as silica coated UCNPs which was cleaned with ethanol/water $(1: 1 v / v)$ and stored in deionized water.

\subsection{Surface Modification on Silica Coated UCNPS}

The above obtained silica coated UCNPs $(10 \mathrm{~mL}, 1 \mathrm{mg} / \mathrm{mL})$ was mixed with acetic acid $(200 \mu \mathrm{L})$ and APS $(10 \mathrm{~mL})$. The resulting mixture was stirred for $180 \mathrm{~min}$ under room ambient temperature. Solid product was collected by centrifugation and finally dried in vacuum at $35^{\circ} \mathrm{C}$ [22].

\subsection{Synthesis of RBO Probe}

First, rhodamine hydrazide was synthesized using rhodamine B and hydrazine hydrate as starting chemicals [23]. Then the probe RBO was synthesized by stirring the mixture of rhodamine hydrazide $(1 \mathrm{mmol})$ and glyoxal $(2 \mathrm{~mL})$ in ethanol $(15 \mathrm{~mL})$ for $18 \mathrm{~h}$ under room temperature. Excess $\mathrm{NaCl}$ powder was added to yield yellow solid which was further purified on a silica gel column and obtained as RBO. RBO was identified by its ${ }^{1} \mathrm{H}$ NMR data (detailed chemical shift values are listed in Supplementary Materials). 


\subsection{Synthesis of UCNPs@SiO $2-R B O$ Nanocomposite}

The above obtained silica coated UCNPs (after being modified with APS, $20 \mathrm{mg}$ ) was mixed with ethanol $(10 \mathrm{~mL})$ and $\mathrm{RBO}(1 \mathrm{mmol})$. The resulting mixture was heated at $80^{\circ} \mathrm{C}$ for $24 \mathrm{~h}$. Solid product was collected by centrifugation, cleaned with ethanol to eliminate excess $\mathrm{RBO}$, and finally dried in vacuum at $35^{\circ} \mathrm{C}$.

\subsection{How to Determine $\mathrm{Hg}^{2+}$ with $\mathrm{UCNPs} @ \mathrm{SiO}_{2}-\mathrm{RBO}$}

A suspension of UCNPs@SiO ${ }_{2}-\mathrm{RBO}$ in ethanol/water $(7: 3, v / v, 0.5 \mathrm{mg} / \mathrm{mL}, \mathrm{pH}=7)$ was firstly prepared and then mixed with certain volume of $\mathrm{Hg}^{2+}$ standard solution. The resulting mixture was treated with ultrasonic bath for $5 \mathrm{~min}$ for a complete mixing, and then sent to record luminescence spectrum. Corresponding excitation and emission wavelengths were set as $980 \mathrm{~nm}$ and $540 \mathrm{~nm}$, respectively.

\section{Results and Discussion}

\subsection{Sensing Performance of $\mathrm{RBO}$ Probe for $\mathrm{Hg}^{2+}$}

It is well known that rhodamine-derived molecules all share a structural transformation between a closed-ring structure and an open-ring one. The former structure is non-fluorescent while the latter one is highly fluorescent [21]. Our probe RBO was designed following this protocol, complying with such structural transformation. To ensure the covalent immobilization of $\mathrm{RBO}$ probe on the $\mathrm{SiO}_{2}$ layer of UCNPs, rhodamine hydrazide was reacted with glyoxal and then connected to the amino groups on the $\mathrm{SiO}_{2}$ layer of UCNPs, so that a nanocomposite $\mathrm{UCNPs} @ \mathrm{SiO}_{2}-\mathrm{RBO}$ was finally obtained. Before discussing the $\mathrm{Hg}^{2+}$-sensing performance of $\mathrm{UCNPs} @ \mathrm{SiO}_{2}-\mathrm{RBO}$, that of probe $\mathrm{RBO}$ is firstly explored as follows.

The absorption spectra of $\mathrm{RBO}$ upon increasing $\mathrm{Hg}^{2+}$ concentration are shown as Figure 1a. The probe RBO obviously responds to $\mathrm{Hg}^{2+}$ [21]. The observation of the increasing absorption intensity at $555 \mathrm{~nm}$ indicates a structural transformation from a closed-ring structure to an open-ring one, which shall be accompanied with an emission turn on effect. The increasing emission intensity is confirmed by the emission spectra of $\mathrm{RBO}$ upon increasing $\mathrm{Hg}^{2+}$ concentration, as shown by Figure $1 \mathrm{~b}$. Additionally, there is a minor emission red shift $\left(570 \mathrm{~nm} \rightarrow 573 \mathrm{~nm}\right.$ ) with increasing $\mathrm{Hg}^{2+}$ concentration. Such emission red shift can be explained by the coordination between $\mathrm{RBO}$ and $\mathrm{Hg}^{2+}$ which forms a rigid structure and depresses the geometric relaxation in excited sate, showing emission red shift.

The chemical stoichiometry of coordination between $\mathrm{RBO}$ and $\mathrm{Hg}^{2+}$ was further analyzed using Job's titration experiment. Here, the total amount of probe $\mathrm{RBO}$ and $\mathrm{Hg}^{2+}$ was preserved, with the molar ratio of $\mathrm{Hg}^{2+}$ increased from $10 \%$ to $90 \%$. Figure 2 shows the emission intensity monitoring at $573 \mathrm{~nm}$. The emission intensity of this $\mathrm{RBO}-\mathrm{Hg}^{2+}$ mixture firstly increases and then reaches a maximum value at $\mathrm{Hg}^{2+}$ molar ratios of $50 \%$. Upon even higher $\mathrm{Hg}^{2+}$ molar ratios, the emission intensity decreases gradually. This result suggests a chemical stoichiometry of $1: 1$ between $\mathrm{RBO}$ and $\mathrm{Hg}^{2+}$, and corresponding coordination reaction can be described as Equation (1). Here, Ks is the association constant for the coordination reaction between $\mathrm{RBO}$ and $\mathrm{Hg}^{2+}$.

$$
\begin{aligned}
\mathrm{RBO}+\mathrm{Hg}^{2+} & \leftarrow \frac{\mathrm{Ks}}{\mathrm{R} B \mathrm{RBH} \mathrm{g}^{2+}} \\
\frac{\alpha}{1-\alpha} & =\frac{1}{\mathrm{Ks}\left[\mathrm{Hg}^{2+}\right]} \\
\alpha & =\frac{A_{T}-A}{A_{T}-A_{0}}
\end{aligned}
$$




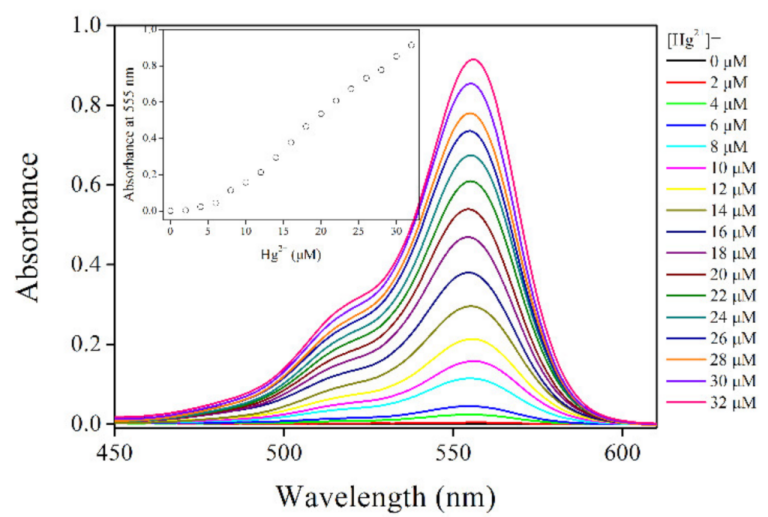

(a)

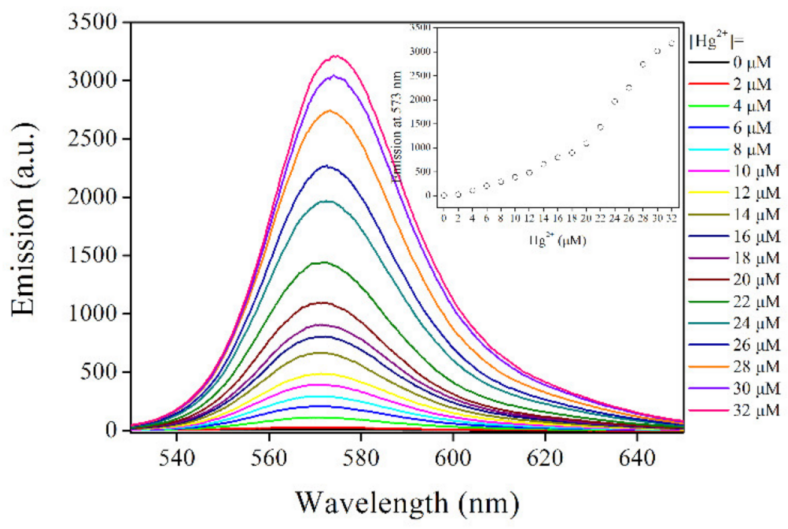

(b)

Figure 1. (a) RBO absorption spectra upon various $\mathrm{Hg}^{2+}$ concentrations and (b) emission spectra upon various $\mathrm{Hg}^{2+}$ concentrations.

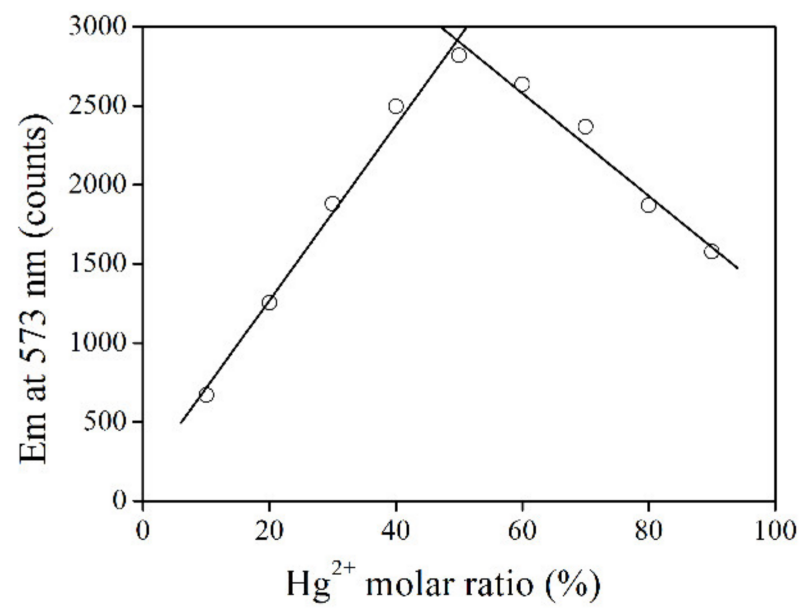

Figure 2. Emission intensity monitoring at $573 \mathrm{~nm}$ upon increasing $\mathrm{Hg}^{2+}$ molar ratio from $10 \%$ to $90 \%$.

Ks of the coordination reaction between $\mathrm{RBO}$ and $\mathrm{Hg}^{2+}$ is then determined by Equations (2) and (3). Here, $A$ is absorbance value, while $A_{T}$ and $A_{0}$ are the critical absorbance values with $\alpha=1$ (fully coordinated with $\mathrm{Hg}^{2+}$ ) and $\alpha=0\left(\right.$ no $\mathrm{Hg}^{2+}$ ), respectively. Based on the absorption spectra in Figure $1, K s$ is calculated as $2.6 \times 10^{5} \mathrm{M}^{-1}$ which is found similar to those of rhodamine-derived probes [21]. With the chemical stoichiometry between $\mathrm{RBO}$ and $\mathrm{Hg}^{2+}$ confirmed, it is assumed that probe $\mathrm{RBO}$ shall follow a simple 
sensing reaction with $\mathrm{Hg}^{2+}$ ions, showing a linear working curve, which consequently benefits sensing operation [21].

Aiming at a fast evaluation on the selectivity of $\mathrm{RBO}$ towards $\mathrm{Hg}^{2+}$, its absorption and emission spectra are recorded in the presence of competing metal cations. It is observed from Figure 3 that RBO shows strong absorption peaking at $555 \mathrm{~nm}$ only in the presence of $\mathrm{Hg}^{2+}$, suggesting a good selectivity. The competing metal cations are all ineffective in triggering RBO structural transformation, leading to the absence of RBO absorption. Correspondingly, this good selectivity is also observed for the RBO emission case. All competing metal cations are powerless to enhance RBO emission, except for two transition metal cations of $\mathrm{Fe}^{3+}$ and $\mathrm{Cr}^{3+}$. Owing to their high ionic charges and thus coordination affinity for RBO, RBO structural transformation is partially initiated by $\mathrm{Fe}^{3+}$ and $\mathrm{Cr}^{3+}$, but their unfilled d orbitals play as an emission quencher, which quenches RBO emission dramatically. Nevertheless, a good selectivity of RBO for $\mathrm{Hg}^{2+}$ can be confirmed here, making RBO a promising probe for further application.

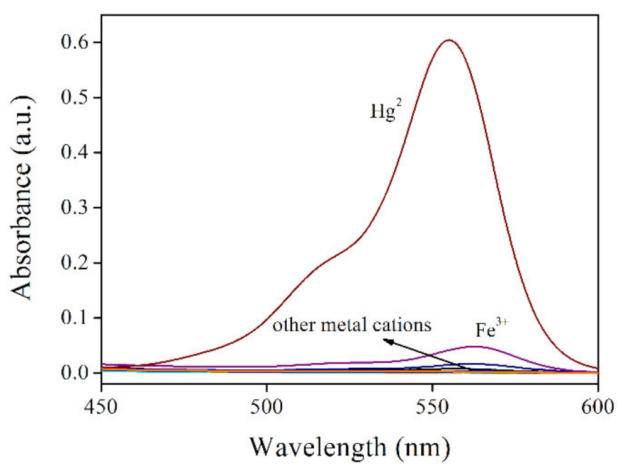

(a)

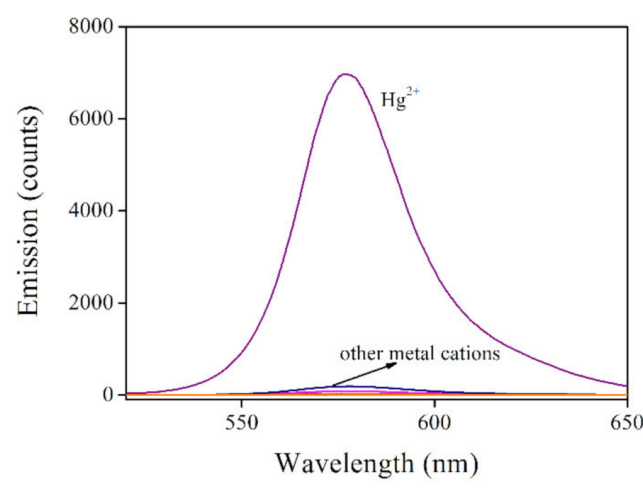

(b)

Figure 3. (a). RBO absorption spectra and (b) RBO emission spectra under some metal cations (RBO:cation = 1:1, molar ratio), including $\mathrm{K}^{+}, \mathrm{Ca}^{2+}, \mathrm{Mg}^{2+}, \mathrm{Pb}^{2+}, \mathrm{Co}^{2+}, \mathrm{Ni}^{2+}, \mathrm{Zn}^{2+}, \mathrm{Cd}^{2+}, \mathrm{Ag}^{+}, \mathrm{Cu}^{2+}$, $\mathrm{Fe}^{3+}$ and $\mathrm{Hg}^{2+}$.

\subsection{Characterization on UCNPs@SiO ${ }_{2}-R B O$}

After confirming the sensing performance of probe $\mathrm{RBO}$, it can be applied for the construction of nanocomposite. It was found that UCNPs with dopants of $\mathrm{Yb}^{3+}$ and $\mathrm{Er}^{3+}$ have perfect spectral overlapping between their emission bands $(\sim 550 \mathrm{~nm})$ and $\mathrm{RBO}$ absorption (centering at $555 \mathrm{~nm}$ ). Scheme 2 illustrates the synthetic route for $\mathrm{UCNPs}_{\mathrm{SSiO}}{ }_{2}-$ RBO, where the UCNPs were used as a secondary excitation source for probe RBO by converting low energy NIR laser $(980 \mathrm{~nm})$ to high energy excitation. These UCNPs were coated with an amorphous $\mathrm{SiO}_{2}$ layer so that any potential negative effect from $\mathrm{Hg}^{2+}$ and probe $\mathrm{RBO}$ are shielded. This $\mathrm{SiO}_{2}$ layer should not be a thick one so that an efficient energy transfer from UCNPs to probe RBO can be finished. UCNPs@SiO $2-\mathrm{RBO}$ is carefully characterized below by their SEM images, XRD patterns, IR spectra and TGA data.

Figure 4 shows the SEM image of as-synthesized UCNPs so that a visual evaluation on their morphology can be observed. Uniform shape with mean diameter of $\sim 40 \mathrm{~nm}$ was observed for these as-synthesized UCNPs. Their XRD pattern is shown in Figure 5, which identified their crystalline nature. These labeled XRD peaks are consistent with those of $\mathrm{NaYF}_{4}$ nanocrystals in hexagonal phase (JCPDS 16-0334), which means that our assynthesized UCNPs were pure hexagonal $\beta-\mathrm{NaYF}_{4}: \mathrm{Yb}^{3+}, \mathrm{Er}^{3+}$ nanoparticles. No diffraction peaks from dopants $\mathrm{Yb}^{3+}$ and $\mathrm{Er}^{3+}$ were observed, indicating that they were successfully doped into $\beta-\mathrm{NaYF}_{4}$ crystals without compromising $\beta-\mathrm{NaYF}_{4}$ crystalline. 

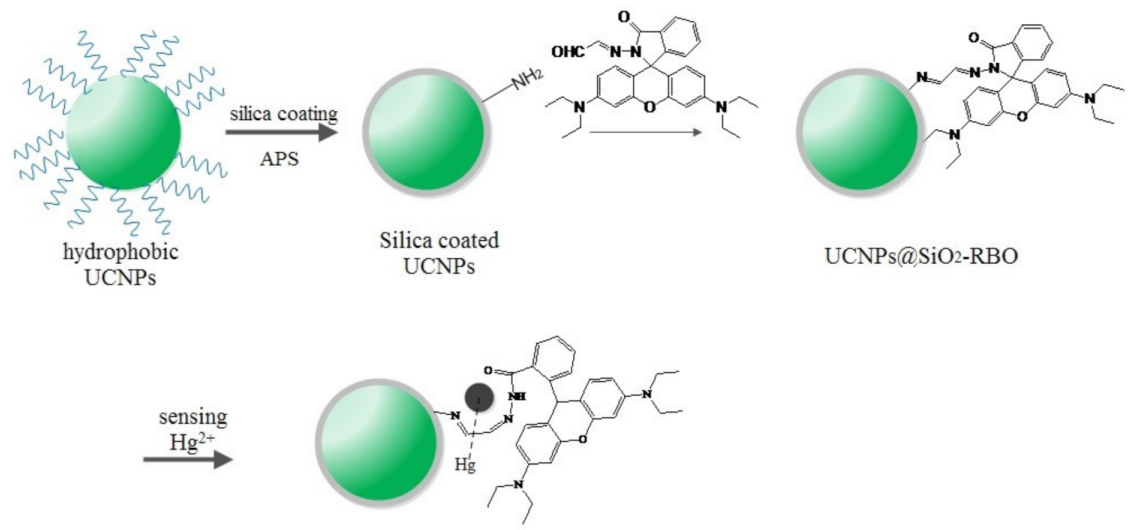

Scheme 2. A synthetic route for probe $\mathrm{RBO}$ and its covalent immobilization onto $\mathrm{SiO}_{2}$ encapsulated UCNPs.

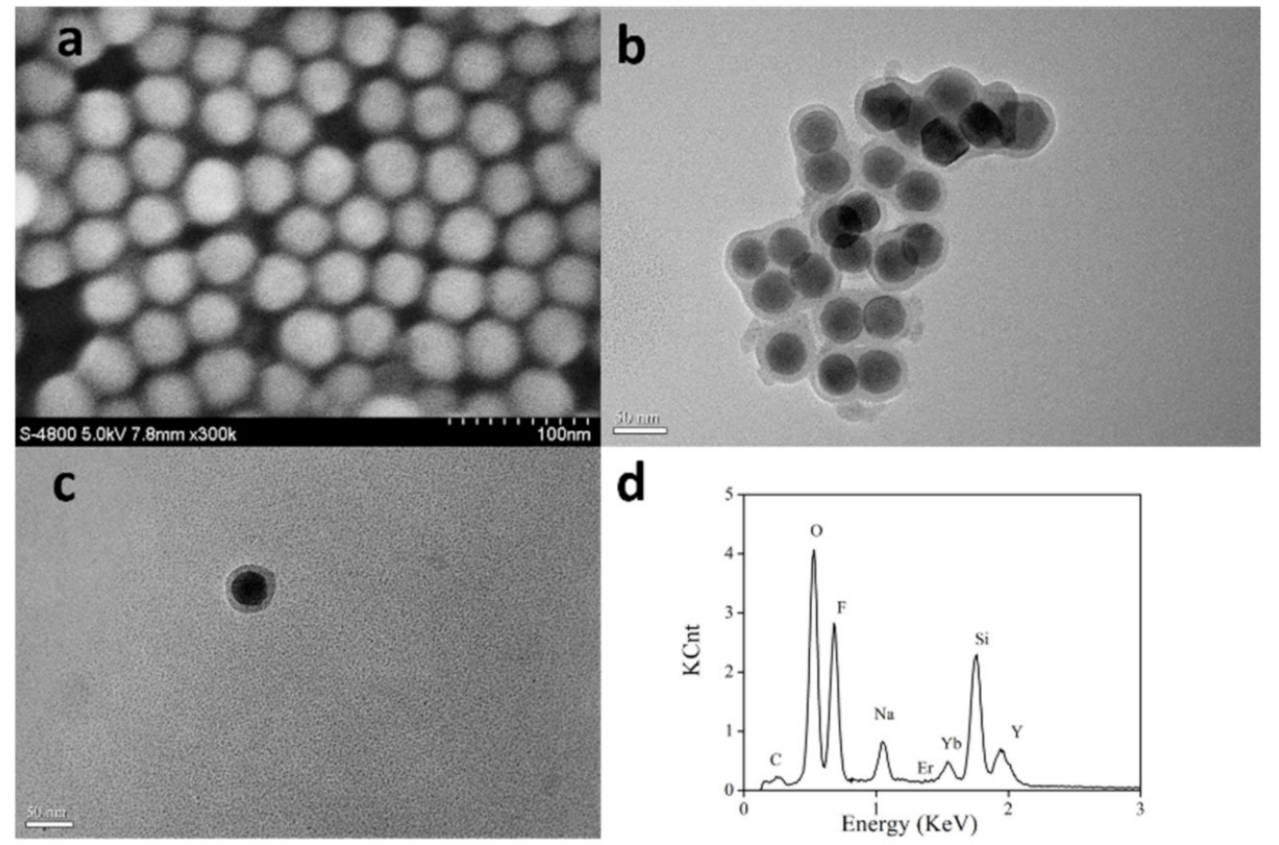

Figure 4. SEM image of as-synthesized UCNPs (a), TEM images of silica coated UCNPs (b) and UCNPs@SiO $2-R B O(\mathbf{c})$, EDX of silica coated UCNPs (d).

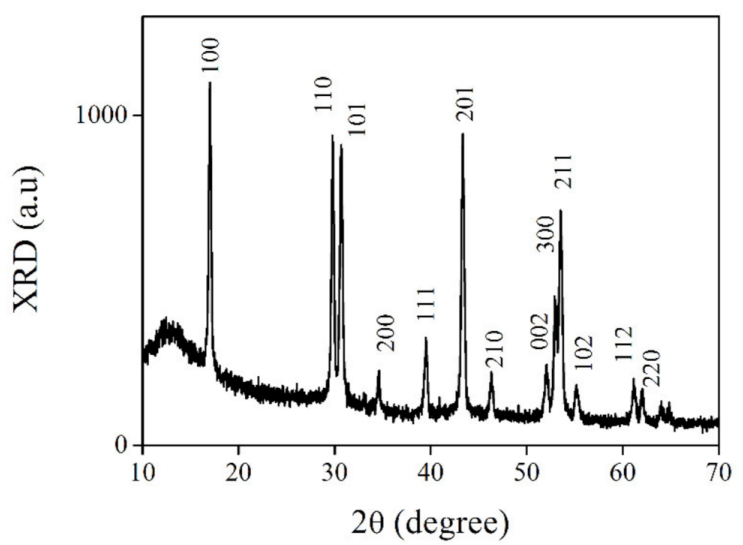

Figure 5. XRD Pattern of As-Synthesized UCNPs. 
For all UCNPs synthesized following a classic method in oleic acid, their surface is fully covered by oleic acid chains and thus is highly hydrophobic. To improve the compatibility with $\mathrm{Hg}^{2+}$ ions in aqueous media, these UCNPs were coated with amorphous $\mathrm{SiO}_{2}$. The resulting silica coated UCNPs were confirmed by their TEM images, as shown in Figure 4. A high resolution TEM suggests that their $\mathrm{SiO}_{2}$ layer was as thin as $8 \mathrm{~nm}$. The successful $\mathrm{SiO}_{2}$ coating can be confirmed by the energy dispersive X-ray (EDX) curves of silica coated UCNPs shown in Figure 4.

The covalent probe grafting had increased the diameter of $\mathrm{UCNPs} @ \mathrm{SiO}_{2}-\mathrm{RBO}$ to $\sim 45 \mathrm{~nm}$, with a similar morphology to the silica coated UCNPs, as shown in Figure 4 . The successful covalent probe grafting between RBO and silica coated UCNPs can be confirmed by comparing the IR spectra of probe RBO, silica coated UCNPs and UCNPs@SiO $\mathrm{S}_{2}-\mathrm{RBO}$. As shown in Figure 6, a strong IR peak of $1737 \mathrm{~cm}^{-1}$ was observed for probe RBO, which can be assigned as the vibration of - $\mathrm{CHO}$ group in RBO. This sharp IR peak is not found from the IR spectrum of UCNPs@SiO $2-\mathrm{RBO}$. A set of IR peaks ranging from 3300 and $3500 \mathrm{~cm}^{-1}$ were assigned as the vibration of $-\mathrm{NH}_{2}$ in amino modified UCNPs. They were not traced in the IR spectrum of UCNPs@SiO $-\mathrm{RBO}$. However, a new IR band peaking at $1622 \mathrm{~cm}^{-1}$ was observed, which was assigned as the vibration of $-\mathrm{N}=\mathrm{CH}$ - group. As a consequence, it is confirmed that probe RBO was successfully immobilized onto the surface of silica coated UCNPs.

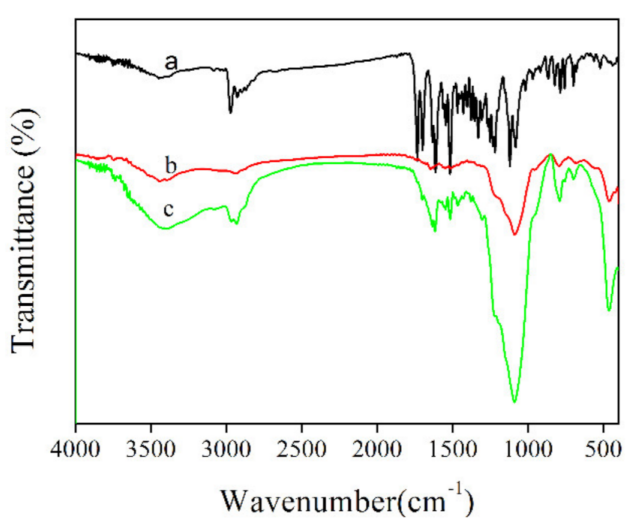

Figure 6. FT-IR spectra of (a) RBO, (b) amino modified UCNPs, (c) UCNPs@SiO $2-R B O$.

The probe loading amount in $\mathrm{UCNPs} @ \mathrm{SiO}_{2}-\mathrm{RBO}$ can be determined by its TGA result. As shown in Figure 7, UCNPs@SiO 2 -RBO TGA curve is composed of three major weight loss steps, which are localized in temperature regions of $80-100{ }^{\circ} \mathrm{C}, 250-380{ }^{\circ} \mathrm{C}$ and $400-550{ }^{\circ} \mathrm{C}$, respectively. The first weight loss is slight and thus assigned as the thermal evaporation of physically absorbed water and residual solvent molecules. The second weight loss region is responsible for a weight loss of $\sim 10.5 \%$, with an endothermic peak of $\sim 360{ }^{\circ} \mathrm{C}$. As a consequence, the probe loading amount is determined as $10.5 \%$ in UCNPs@SiO ${ }_{2}-\mathrm{RBO}$. Considering this high temperature and obvious weight loss, it is assigned as the thermal destruction of organic probe in UCNPs@SiO${ }_{2}-\mathrm{RBO}$. The final weight loss region can be assigned as the thermal degradation and collapse of organosilicate frameworks, such as the cleavage of Si-C, C-C and C-N bonds [24,25].

\subsection{Energy Transfer in UCNPs@SiO $\mathrm{O}_{2}-\mathrm{RBO}$}

The above result confirms a nanocomposite structure for $\mathrm{Hg}^{2+}$-sensing, which is based on an energy transfer (ET) procedure from UCNPs to $\mathrm{Hg}^{2+}$-sensitive probe RBO. Upon NIR laser of $980 \mathrm{~nm}$, UCNPs excite probe RBO to accomplish the sensing operation. 


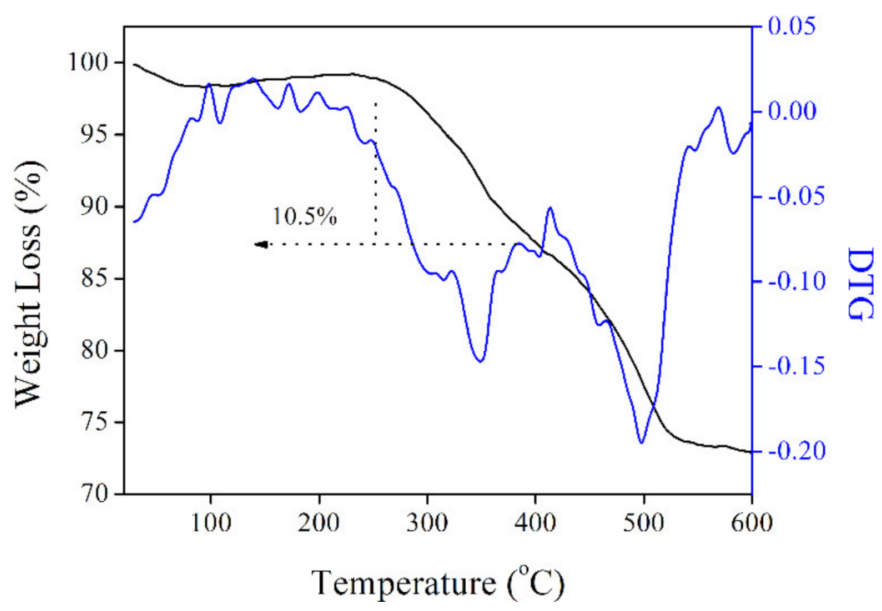

Figure 7. TGA and DTG (differential thermal gravity) curves of UCNPs@SiO $2-\mathrm{RBO}$.

For the better understanding on the energy transfer between UCNPs and probe RBO, the upconversion emission spectrum of UCNPs and the absorption spectra of RBO, with or without $\mathrm{Hg}^{2+}$, are shown in Figure 8. Upon NIR laser excitation of $980 \mathrm{~nm}$, the UCNPs exhibited a major emission band peaking at $540 \mathrm{~nm}$ and a shoulder emission band peaking at $521 \mathrm{~nm}$, which can be attributed to ${ }^{2} \mathrm{H}_{11 / 2}$ to ${ }^{4} \mathrm{I}_{15 / 2}$ transition and ${ }^{4} \mathrm{~S}_{3 / 2}$ to ${ }^{4} \mathrm{I}_{15 / 2}$ transition of $\mathrm{Er}^{3+}$. There was still a weak band peaking at $650 \mathrm{~nm}$ which belonged to the ${ }^{4} \mathrm{~F}_{9 / 2}$ to ${ }^{4} \mathrm{I}_{15 / 2}$ transition of $\mathrm{Er}^{3+}$. Pure RBO has no obvious absorption within $450 \mathrm{~nm}$ to $700 \mathrm{~nm}$. After bonding with $\mathrm{Hg}^{2+}$, a strong absorption around $555 \mathrm{~nm}$ was observed, which overlaps well with the first two upconversion emission bands of UCNPs, indicating a possibility of energy transfer from UCNPs to RBO. The efficiency of such energy transfer can be evaluated by the Forster radius $\left(R_{0}\right)$ between donor and acceptor, using Equation (4). Here, $Q_{0}$ is the intrinsic emission yield of donor in the absence of acceptor, which has been reported as $3 \%$ for UCNPs [21]. $J$ is the spectral overlap integral between donor emission and acceptor absorption spectra. $\kappa^{2}$ is mutual molecular orientation factor, $N_{A}$ is Avogadro number and $n_{d}$ is solvent refraction index, respectively.

$$
\begin{gathered}
R_{0}^{6}=\frac{9 Q_{0} k^{2} J(\ln 10)}{128 \pi^{5} n_{d}^{4} N_{A}} \\
J=\int f_{D}(\lambda) \varepsilon_{A}(\lambda) \lambda^{4} d \lambda
\end{gathered}
$$

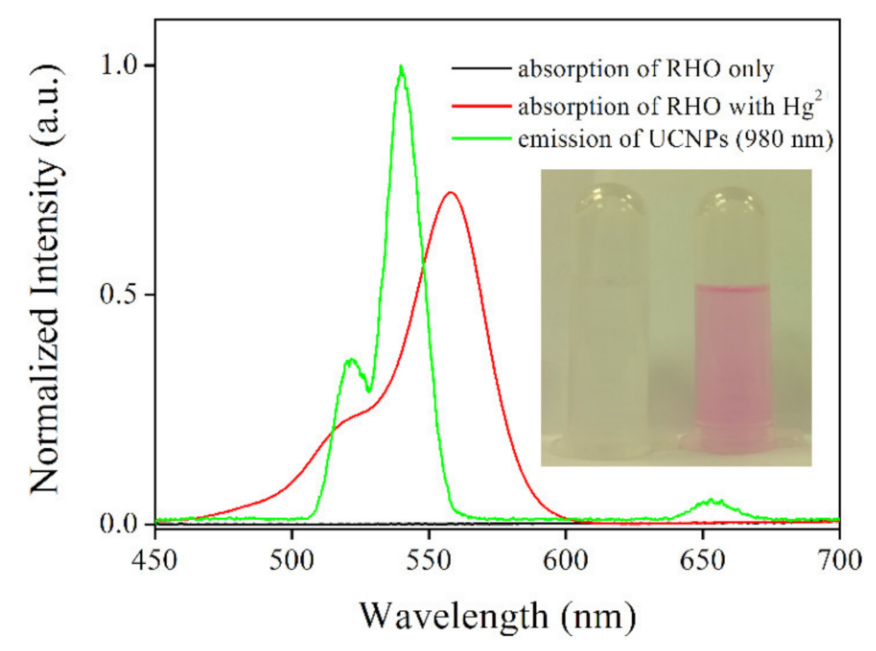

Figure 8. Absorption spectra of $\mathrm{RBO}$ and $\mathrm{RBO}$ upon addition of $\mathrm{Hg}^{2+}$, and emission spectrum of UCNPs (excitation wavelength $=980 \mathrm{~nm}$ ). Inset: A photo of UCNPs@SiO $2-\mathrm{RBO}$ without $\mathrm{Hg}^{2+}$ and with $\mathrm{Hg}^{2+}$. 
It is observed from Equation (4) that an efficient energy transfer depends on a good spectral overlap between donor emission and acceptor absorption, which has been above confirmed in Figure 8. Additionally, the distance between donor and acceptor has been determined as $8 \mathrm{~nm}$, which is also the thickness of $\mathrm{SiO}_{2}$ layer. This short distance is positive to improve the energy transfer process. Thus, a fluent energy transfer from UCNPs to RBO can be expected, so that UCNPs green emission can be quenched, showing sensing signal. There is still one issue to be addressed, though. Theoretically, by decreasing the thickness of $\mathrm{SiO}_{2}$ layer, the distance between donor and acceptor can be decreased, which is supposed to improve the fluorescence resonance energy transfer (FRET) efficiency. On the other hand, a thin layer may lead to the exposure of UCNPs, compromising sensing performance.

\subsection{Sensing Performance of UCNPs@SiO ${ }_{2}-R B O$}

The $\mathrm{Hg}^{2+}$-sensing performance of UCNPs@SiO $-\mathrm{RBO}$ was then analyzed by discussing its emission spectra upon increasing $\mathrm{Hg}^{2+}$ concentrations. It is observed from Figure 9 that, upon the NIR laser excitation of $980 \mathrm{~nm}$, the upconversion emission intensity of UCNPs@SiO $\mathrm{U}_{2}-\mathrm{RBO}$ gradually decreased with $\mathrm{Hg}^{2+}$ concentration increased from 0 to $35 \mu \mathrm{M}$, showing emission quenching effect. This result actually indicates an energy transfer from UCNPs to probe RBO. For comparison convenience, these emission spectra were analyzed with a modified equation of Stern-Volmer equation, as described as Figure 9 inset. The corresponding regression equation is fitted as $\mathrm{I} / \mathrm{I}_{0}=5.74-0.134\left[\mathrm{Hg}^{2+}\right]$ $\left(R^{2}=0.9992\right)$ with good linearity. The limit of detection (LOD) was determined as $2.2 \mu \mathrm{M}$ $(3 \sigma / N)$. This value is found comparable to or even slightly lower than those of similar FRET-based sensing systems for detecting metal cations, as shown in Table 1.

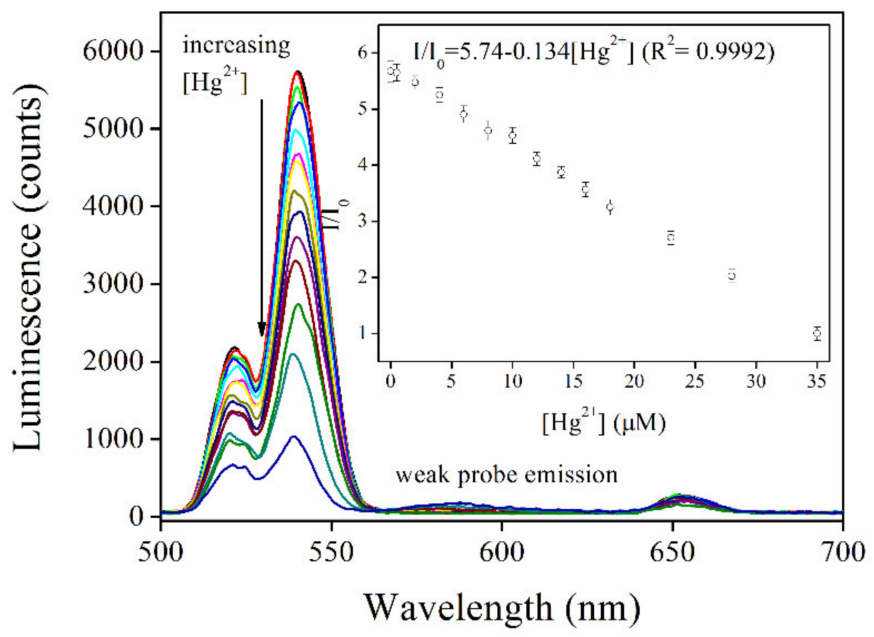

Figure 9. Emission spectra of UCNPs@SiO $2-\mathrm{RBO}(0.5 \mathrm{mg} / \mathrm{mL})$ with increasing $\mathrm{Hg}^{2+}$ concentration from $0-35 \mu \mathrm{M}$ in ethanol-water solution $(\mathrm{V}: \mathrm{V}=7: 3)$. Inset: linear fitting of $\mathrm{I} / \mathrm{I}_{0}$ against $\mathrm{Hg}^{2+}$ concentration.

There is an interesting fact worthy of further explanation, though. Even though the probe RBO accepts UCNPs energy and quenches UCNPs emission, there is no obvious RBO emission, which is rather different from the case of free RBO. It has been above confirmed in Figure 1 that $\mathrm{RBO}$ shows strong fluorescence in the presence of $\mathrm{Hg}^{2+}$. In this case, it is tentatively assumed that the absence of RBO emission in UCNPs@SiO by the self-absorption and self-quenching between probe molecules. It is observed from Figure 1 that the Stokes shift between RBO absorption $(555 \mathrm{~nm})$ and emission $(573 \mathrm{~nm})$ is rather slim, with efficient spectral overlap between $\mathrm{RBO}$ absorption and emission spectra. Due to the restriction of secondary excitation mechanism and the low quantum yield of UCNPs ( $3 \%)$, RBO emission is weak. This weak emission may be absorbed by surrounding $\mathrm{RHO}$ molecules in ground state. As a consequence, no obvious RBO emission shows. 
Table 1. Key sensing parameters of UCNPs@SiO $2-\mathrm{RBO}$ and literature systems. LOD = limit of detection.

\begin{tabular}{|c|c|c|c|c|c|}
\hline Name & Sensitivity & Sensing Type & Linearity & LOD & Ref. \\
\hline $\begin{array}{c}{\mathrm{UCNPs} @ \mathrm{SiO}_{2}-}^{\mathrm{RHO}} \\
\end{array}$ & 5.67 & quenching & linear & $2.2 \mu \mathrm{M}$ & this work \\
\hline $\begin{array}{l}\text { UCNPs\&RB- } \\
\text { hydrazide }\end{array}$ & $\sim 2.9$ & ratiometric & linear & $10^{-6} \mathrm{M}$ & [26] \\
\hline Si-RH & $\sim 2.2$ & emission turn on & linear & $2.7 \mathrm{nM}$ & [23] \\
\hline CS1 & $\sim 0.4$ & absorption turn on & linear & $\mathrm{N} / \mathrm{A}$ & [27] \\
\hline $\mathrm{RbCS}$ & $\mathrm{N} / \mathrm{A}$ & emission turn on & non-linear & $\mathrm{N} / \mathrm{A}$ & [28] \\
\hline
\end{tabular}

Finally, the sensing selectivity of UCNPs@SiO $2-\mathrm{RBO}$ for $\mathrm{Hg}^{2+}$ is discussed as follows. Some common interfering metal cations were selected here, including $\mathrm{K}^{+}, \mathrm{Ca}^{2+}, \mathrm{Mg}^{2+}$, $\mathrm{Pb}^{2+}, \mathrm{Co}^{2+}, \mathrm{Ni}^{2+}, \mathrm{Zn}^{2+}, \mathrm{Cd}^{2+}, \mathrm{Ag}^{+}, \mathrm{Cu}^{2+}$ and $\mathrm{Fe}^{3+}$. Their nitrate salts were added into the solution of $\mathrm{UCNPs} @ \mathrm{SiO}_{2}-\mathrm{RBO}$; corresponding emission intensity variation is shown in Figure 10. It was observed that these interfering metal cations exert no obvious effect on the luminescence intensity of $\mathrm{UCNPs} @ \mathrm{SiO}_{2}-\mathrm{RBO}$. Only the presence of $\mathrm{Hg}^{2+}$ leads to an obvious emission quenching. Even in a mixture of these interfering metal ions, such luminescence quenching was still observed. This good selectivity can certainly be attributed to probe $\mathrm{RBO}^{\prime} \mathrm{s}$ unique sensing mechanism towards $\mathrm{Hg}^{2+}$, and after being immobilized onto the surface of UCNPs, such good selectivity is still preserved. Hereby, it is finally concluded that $\mathrm{UCNPs} @ \mathrm{SiO}_{2}-\mathrm{RBO}$ is a selective $\mathrm{Hg}^{2+}$-sensing nanocomposite excited by NIR laser of $980 \mathrm{~nm}$.

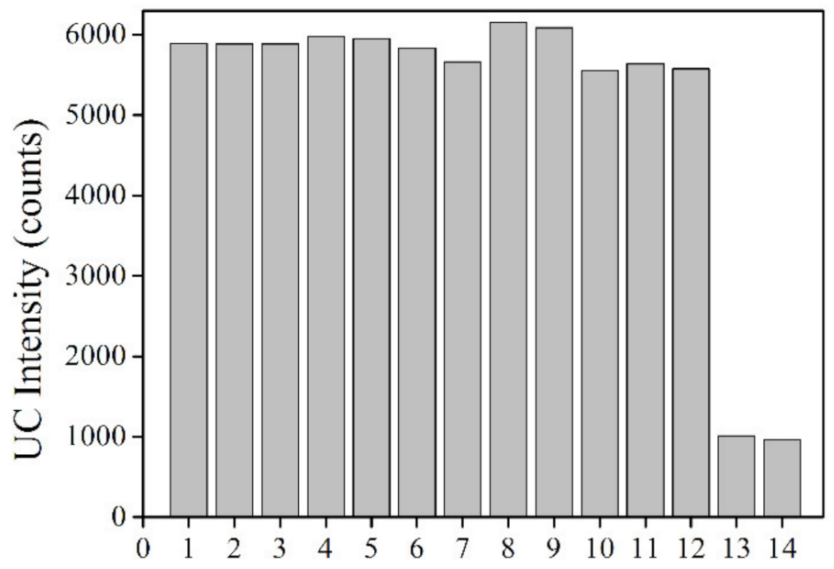

Figure 10. Interfering metal cations effect $(100 \mu \mathrm{M})$ on emission intensity of UCNPs@SiO $\mathrm{U}_{2}-\mathrm{RBO}$ $(0.5 \mathrm{mg} / \mathrm{mL})$ in ethanol-water solution $(\mathrm{V}: \mathrm{V}=7: 3) .1=$ no ion, $2=\mathrm{K}^{+}, 3=\mathrm{Ca}^{2+}, 4=\mathrm{Pb}^{2+}, 5=\mathrm{Mg}^{2+}$, $6=\mathrm{Co}^{2+}, 7=\mathrm{Ni}^{2+}, 8=\mathrm{Zn}^{2+}, 9=\mathrm{Cd}^{2+}, 10=\mathrm{Ag}^{+}, 11=\mathrm{Cu}^{2+}, 12=\mathrm{Fe}^{2+}, 13=\mathrm{Hg}^{2+}$ (only), $14=\mathrm{Hg}^{2+}$ (mixed with all the above metal ions).

\section{Conclusions}

In this paper, we reported a rhodamine-derived probe $\mathrm{RBO}$ for $\mathrm{Hg}^{2+}$ sensing. It was found that both $\mathrm{RBO}$ absorption and emission intensity were increased with increasing $\mathrm{Hg}^{2+}$, showing obvious sensing signal. The chemical stoichiometry analysis suggested a simple coordination reaction between $\mathrm{RBO}$ and $\mathrm{Hg}^{2+}$ with molar ratio of 1:1. The association constant was determined as $2.6 \times 10^{5} \mathrm{M}^{-1}$. This high affinity confirmed a coordination reaction between $\mathrm{RBO}$ and $\mathrm{Hg}^{2+}$. Probe $\mathrm{RBO}$ showed good selectivity for $\mathrm{Hg}^{2+}$, even in the presence of interfering metal cations. By covalently grafting $\mathrm{RBO}$ onto UCNPs, a nanocomposite sensing system was constructed, which absorbed NIR laser excitation of $980 \mathrm{~nm}$ and transferred this energy to probe RBO, showing the emission quenching effect of UCNPs. A linear working curve was observed, with LOD value of $2.2 \mu \mathrm{M}$. There was an interesting fact that had never been reported by other references, 
which was the emission absence of probe RBO, even though it accepted UCNPs energy. The self-absorption and self-quenching between probe molecules was claimed responsible for this phenomenon. This UCNPs-based nanocomposite applied NIR as excitation source. As a consequence, low background noise of autofluorescence was observed. This method can be used as a promising pathway for the detection in biological samples.

Supplementary Materials: The following are available online at https:/ /www.mdpi.com/2073-435 2/11/2/104/s1.

Author Contributions: W.W. (Wei Wu) was responsible for original draft, review and final editing. W.W. (Wei Wei) was responsible for methodology. D.X. was responsible for experiment investigation. Y.L. was responsible for formal analysis of experiment result. J.L. was responsible for supervision and software application. K.G. was responsible for supervision. L.L. was responsible for draft preparation, writing, review and editing. All authors have read and agreed to the published version of the manuscript.

Funding: This research was funded by the Natural Science Foundation of Zhejiang, China (Grant No. LQ21H060002), Zhejiang Provincial Natural Science Foundation of China under Grant No.LQ20H060002, the Natural Science Foundation of Ningbo, China (Grant No. 2019A610247 and Grant No. 202003N4324), "Scientific and Technological innovation 2025" Major Project (Grant No.2019B10062), Research Foundation of Hwa Mei Hospital, University of Chinese Academy of Sciences, China (Grant No.2020HMKY16) and Project of the Science and Technology Plan for Zhejiang Province(LGF21F020022) and The APC was funded by Zhejiang Provincial Natural Science Foundation of China under Grant No.LQ20H060002 and "Scientific and Technological innovation 2025" Major Project (Grant No.2019B10062).

Acknowledgments: The authors gratefully thank below financial supports, including the Natural Science Foundation of Zhejiang, China (Grant No. LQ21H060002), Zhejiang Provincial Natural Science Foundation of China under Grant No.LQ20H060002, the Natural Science Foundation of Ningbo, China (Grant No. 2019A610247 and Grant No. 202003N4324), “Scientific and Technological innovation 2025" Major Project (Grant No.2019B10062), Research Foundation of Hwa Mei Hospital, University of Chinese Academy of Sciences, China (Grant No.2020HMKY16) and Project of the Science and Technology Plan for Zhejiang Province(LGF21F020022).

Conflicts of Interest: The authors declare no conflict of interest.

\section{References}

1. Wang, Q.; Kim, D.; Dionysiou, D.D.; Sorial, G.A.; Timberlake, D. Sources and remediation for mercury contamination in aquatic systems-a literature review. Environ. Pollut. 2004, 131, 323. [CrossRef] [PubMed]

2. Nolan, E.M.; Lippard, S.J. A “Turn-On" fluorescent sensor for the selective detection of mercuric ion in aqueous media. J. Am. Chem. Soc. 2003, 125, 14270. [CrossRef] [PubMed]

3. Yoon, S.; Miller, E.W.; He, Q.; Do, P.H.; Chang, C.J. A bright and specific fluorescent sensor for mercury in water, cells, and tissue. Angew. Chem. Int. Ed. 2007, 46, 6658. [CrossRef] [PubMed]

4. Wanichancheva, N.; Setthakarn, K.; Prapawattanapol, N.; Hanmeng, O.; Lee, V.S.; Grudpan, K. Rhodamine B-based "turn-on" fluorescent and colorimetric chemosensors for highly sensitive and selective detection of mercury (II) ions. J. Lumin. 2012, 132, 35. [CrossRef]

5. Park, M.; Seo, S.; Lee, I.S.; Jung, J.H. Ultraefficient separation and sensing of mercury and methylmercury ions in drinking water by using aminonaphthalimide-functionalized $\mathrm{Fe}_{3} \mathrm{O}_{4} @ \mathrm{SiO}_{2}$ core/shell magnetic nanoparticles. Chem. Commun. 2010, 46, 4478. [CrossRef]

6. Duan, J.; Jiang, X.; Ni, S.; Yang, M.; Zhan, J. Facile synthesis of N-acetyl-1-cysteine capped ZnS quantum dots as an eco-friendly fluorescence sensor for $\mathrm{Hg}^{2+}$. Talanta 2011, 85, 1738. [CrossRef]

7. Li, H.; Wang, L. $\mathrm{NaYF}_{4}: \mathrm{Yb}^{3+} / \mathrm{Er}^{3+}$ nanoparticle-based upconversion luminescence resonance energy transfer sensor for mercury(II) quantification. Analyst 2013, 138, 1589. [CrossRef]

8. Li, C.; Liu, J.; Alonso, S.; Li, F.; Zhang, Y. Upconversion nanoparticles for sensitive and in-depth detection of $\mathrm{Cu}^{2+}$ ions. Nanoscale 2012, 4, 6065. [CrossRef]

9. Li, C.; Lin, J. Rare earth fluoride nano-/microcrystals: Synthesis, surface modification and application. J. Mater. Chem. 2010, 20, 6831. [CrossRef]

10. Haase, M.; Schafer, H. Upconverting nanoparticles. Angew. Chem. Int. Ed. 2011, 50, 5808. [CrossRef]

11. Chatterjee, D.K.; Rufaihah, A.J.; Zhang, Y. Upconversion fluorescence imaging of cells and small animals using lanthanide doped nanocrystals. Biomaterials 2008, 29, 937. [CrossRef] [PubMed] 
12. Bouzigues, C.; Gacoin, T.; Alexandrou, A. Biological applications of rare-earth based nanoparticles. ACS Nano. $2011,5,8488$. [CrossRef] [PubMed]

13. Shan, G.; Weissleder, R.; Hilderbrand, S.A. Upconverting organic dye doped core-shell nano-composites for dual-modality nir imaging and photo-thermal therapy. Theranostics 2013, 3, 267. [CrossRef] [PubMed]

14. Pierre, A.T.V.C. Principles of responsive lanthanide-based luminescent probes for cellular imaging. Anal. Bioanal. Chem. 2009, 394, 107.

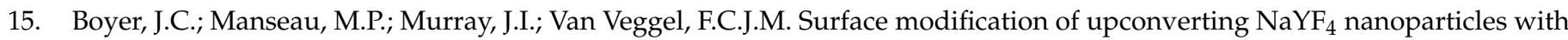
peg-phosphate ligands for nir $(800 \mathrm{~nm})$ biolabeling within the biological window. Langmuir 2010, 26, 1157. [CrossRef]

16. Liu, J.; Cheng, J.; Zhang, Y. Upconversion nanoparticle based LRET system for sensitive detection of MRSA DNA sequence. Biosens. Bioelectron. 2013, 43, 252. [CrossRef]

17. Wang, L.; Yan, R.; Huo, Z.; Wang, L.; Zeng, J.; Bao, J.; Wang, X.; Peng, Q.; Li, Y. Fluorescence resonant energy transfer biosensor based on upconversion-luminescent nanoparticles. Angew. Chem. Int. Ed. 2005, 44, 6054. [CrossRef]

18. Yao, L.; Zhou, J.; Liu, J.; Feng, W.; Li, F. Iridium-complex-modified upconversion nanophosphors for effective lret detection of cyanide anions in pure water. Adv. Funct. Mater. 2012, 22, 2667. [CrossRef]

19. Siefe, C.; Mehlenbacher, R.D.; Peng, C.S.; Zhang, Y.; Fischer, S.; Lay, A.; McLellan, C.A.; Alivisatos, A.P.; Chu, S.; Dionne, J.A. Sub-20 nm core-shell-shell nanoparticles for bright upconversion and enhanced förster resonant energy transfer. J. Am. Chem. Soc. 2019, 141, 16997-17005. [CrossRef]

20. Kang, D.; Lee, S.; Shin, H.; Pyun, J.; Lee, J. An efficient NIR-to-NIR signal-based LRET system for homogeneous competitive immunoassay. Biosens. Bioelectron. 2020, 150, 111921. [CrossRef]

21. Li, Z.; Liang, T.; Wang, Q.; Liu, Z. Strategies for constructing upconversion luminescence nanoprobes to improve signal contrast. Small 2020, 16, 1905084. [CrossRef] [PubMed]

22. Yuan, P.; Lee, Y.H.; Gnanasammandhan, M.K.; Guan, Z.; Zhang, Y.; Xu, Q.H. Plasmon enhanced upconversion luminescence of $\mathrm{NaYF}_{4}: \mathrm{Yb}, \mathrm{Er} @ S i \mathrm{~S}_{2} @ \mathrm{Ag}$ core-shell nanocomposites for cell imaging. Nanoscale 2012, 4, 5132. [CrossRef] [PubMed]

23. Ni, J.; Li, Q.; Li, B.; Zhang, L. A novel fluorescent probe based on rhodamine B derivative for highly selective and sensitive detection of mercury(II) ion in aqueous solution. Sens. Actuators B 2013, 186, 278. [CrossRef]

24. Li, Y.J.; Yan, B. Lanthanide $\left(\mathrm{Eu}^{3+}, \mathrm{Tb}^{3+}\right) / \beta$-diketone modified mesoporous sba-15/organic polymer hybrids: Chemically bonded construction, physical characterization, and photophysical properties. Inorg. Chem. 2009, 48, 8276. [CrossRef] [PubMed]

25. Wang, L.; Li, B.; Zhang, L.; Zhang, L.; Zhao, H. Fabrication and characterization of a fluorescent sensor based on Rh 6Gfunctionlized silica nanoparticles for nitrite ion detection. Sens. Actuators B 2012, 171-172, 946. [CrossRef]

26. Zhang, J.; Li, B.; Zhang, L.; Jiang, H. An optical sensor for $\mathrm{Cu}(\mathrm{II})$ detection with upconverting luminescent nanoparticles as an excitation source. Chem. Commun. 2012, 48, 4860. [CrossRef]

27. Xie, X.; Chen, X.; Li, B.; Zhang, L. Study on a highly selective colorimetric chemosensor for $\mathrm{Cu}^{2+}$ detection and its indirect sensing for hypochlorite. Dye. Pigment. 2013, 98, 433. [CrossRef]

28. Yang, Y.; Gao, C.; Li, B.; Xu, L.; Duan, L. A rhodamine-based colorimetric and reversible fluorescent chemosensor for selectively detection of $\mathrm{Cu}^{2+}$ and $\mathrm{Hg}^{2+}$ ions. Sens. Actuators B 2014, 199, 121. [CrossRef] 